\title{
Hippocampus Gray Matter Atrophy Happens More Seriously in AD Female Patients
}

\author{
Iman Beheshti ${ }^{*}$, Hiroshi Matsuda1, Farnaz Farokhian², Chunlan Yang2 \\ ${ }^{1}$ Integrative Brain Imaging Center, National Center of Neurology and Psychiatry, Tokyo, Japan \\ ${ }^{2}$ College of Life Science and Bioengineering, Beijing University of Technology, Beijing, China \\ Email: *Iman.beheshti@ncnp.go.jp
}

How to cite this paper: Beheshti, I., Matsuda, H., Farokhian, F. and Yang, C.L. (2016) Hippocampus Gray Matter Atrophy Happens More Seriously in AD Female Patients. J. Biomedical Science and Engineering, 9, 180-186.

http://dx.doi.org/10.4236/jbise.2016.910B023

Received: September 16, 2016 Accepted: September 20, 2016 Published: September 23, 2016

\begin{abstract}
Hippocampus, an area of cortex that plays an important role in thinking, planning and remembering. In Alzheimer's disease (AD), the hippocampus is one of the first areas of the brain to become shriveled and this leads to the memory less, damage in learning and declaration of emotional behaviors. In this paper, we investigate the effects of sex on hippocampus gray matter (HGM) atrophy in four groups of participants, namely, males with $\mathrm{AD}(\mathrm{M}-\mathrm{AD}, \mathrm{n}=34)$, age-matched normal male controls (M-NC, $\mathrm{n}=34)$, females with $\mathrm{AD}(\mathrm{F}-\mathrm{AD}, \mathrm{n}=34)$, and age matched normal female controls $(\mathrm{F}-\mathrm{NC}, \mathrm{n}=34)$ from ADNI dataset. In this regard, Analysis of variance (ANOVA) is employed to compare means of HGM differences among groups. The statistical results obtained by ANOVA show that the distribution of HGM atrophy is effected by sex. Also there was a significant diagnosis with higher severity in the $\mathrm{F}-\mathrm{AD}$ compared to $\mathrm{M}-\mathrm{AD}$. The $\mathrm{AD}$ studies based on the sex may help to figure out the root of $\mathrm{AD}$ mechanisms and potentially can be used as an imaging marker for the studies of $\mathrm{AD}$ in the future.
\end{abstract}

\section{Keywords}

Alzheimer's Disease, Hippocampus, Statistical Analysis, Sex, Gray Matter Atrophy

\section{Introduction}

In older adults, Alzheimer's disease (AD), gradually destroys regions of the brain that are responsible for memory, learning, thinking, and behavior [1] [2]. Investigators demonstrated a link between subjective memory lapses and lower hippocampal volume. Recently, several studies have investigated the role of hippocampus in the AD [3]-[6]. Hippocampus volume change has huge potential as a marker at early stages of $\mathrm{AD}$ [7]. In addition to age, family history, apolipoprotein $\mathrm{E}$ (APOE)-e4 and genetics which are 
the main factors in development of $\mathrm{AD}$, sex is also an important factor in people who suffer from $\mathrm{AD}[8]$ [9].

The aim of this study is to investigate hippocampus gray matter (HGM) atrophy in $\mathrm{AD}$ base on sex using structural MRI (sMRI). sMRI is a powerful biomarker of the stage and intensity of the neurodegenerative aspect of AD pathology [10] [11].

In this regard, a cross-sectional analysis using sMRI is employed to inquire differences in HGM atrophy in AD. In this study, overall HGM volume are investigated using analysis of variance (ANOVA) among four groups of participants. The four groups: males with $\mathrm{AD}(\mathrm{M}-\mathrm{AD}, \mathrm{n}=34)$, normal male controls $(\mathrm{M}-\mathrm{NC}, \mathrm{n}=34)$, females with $\mathrm{AD}(\mathrm{F}-\mathrm{AD}, \mathrm{n}=34)$, and age matched normal female controls (F-NC, $\mathrm{n}=34)$.

The statistical analysis among four groups shows that females with $\mathrm{AD}$ have more significant atrophy in the Hippocampus area, compared to males with AD. Furthermore, our findings suggest that there may be a link between HGM atrophy and AD based on the sex. Sex differences research in AD aims to improve early diagnosis, ensure a better quality of life, and develop more effective treatments.

\section{Materials and Subjects}

The MRIs and data used in this paper are obtained from the ADNI database ${ }^{1}$. The MRI scans are acquired using 3 Tesla, T1-weighted by Siemens scanner with TE/TI/TR = $2.98 / 900 / 2300 \mathrm{~ms}$, slice thickness $=1.2 \mathrm{~mm}$, flip angle $=9$ degrees, Rows $\times$ Cols $\times$ Slices $=176 \times 240 \times 256$, and voxel size of $1.2 \times 1.05 \times 1.05 \mathrm{~mm}$. All the subjects initially underwent a number of neuropsychological examinations including the Mini Mental State Examination (MMSE) and Clinical Dementia Ratio (CDR) scores.

We have randomly obtained 200 subjects from ADNI data ${ }^{1}$ database. A quota sampling technique was then employed to choose 136 samples, which were matched on the basis of age and clinical characteristics (e.g. MMSE and CDR) and divided in four groups (Table 1). Table 1 shows the characteristics of subjects used in this study.

Table 1. Characteristics of subjects according to sex.

\begin{tabular}{ccccc}
\hline & F-AD & F-NC & M-AD & M-NC \\
\hline Age & $74.01 \pm 7.09$ & $74.032 \pm 4.79$ & $74.64 \pm 5.71$ & $74.25 \pm 5.18$ \\
Number & 34 & 34 & 34 & 34 \\
Sex(f/m)\% & $100 / 0$ & $100 / 0$ & $0 / 100$ & $0 / 100$ \\
MMSE & $22.73 \pm 2.43$ & $29.38 \pm 0.69$ & $22.73 \pm 2.72$ & $29.38 \pm 0.73$ \\
CDR & $0.75 \pm 0.39$ & $0.0 \pm 0$ & $0.75 \pm 0.39$ & $0.0 \pm 0$ \\
\hline
\end{tabular}

Note: All data present in mean \pm standard deviation mode. $\mathrm{AD}=$ Alzheimer's Disease patients, $\mathrm{CDR}=\mathrm{Clinical}$ Dementia Rating, NC $=$ Normal Control patients, MMSE $=$ Mini-Mental State Examination.

${ }^{1}$ www.loni.ucla.edu/ADNI. 


\section{Methods}

Figure 1 show the framework of the proposed system for calculation hippocampus volumes. Briefly, All MRIs are corrected for bias field in homogeneities, normalized and segmented into gray matter (GM), white matter (WM), and cerebrospinal fluid (CSF) using the Statistical Parameter Mapping (SPM) and the VBM toolbox . A nonlinear deformation is used to modulate the normalized and segmented images. All the images from ADNI database are resized to $121 \times 145 \times 121$ with voxel size of $1.5 \times 1.5 \times 1.5$ $\mathrm{mm}$.

In this study, only GM images are used. Finally, full-width-half-maximum (FWHM) Gaussian kernel is used with $8 \mathrm{~mm}$ kernel size is employed for spatial smoothing of the GM images. After spatial pre-processing, the MarsBaR toolbox is employed to calculate right and left HGM volumes from the normalized, smoothed, modulated, gray matter datasets. In addition, the ANOVA followed by a Tukey multiple comparison test ( $\mathrm{p}<$ 0.05) using Statistical Package for Social Sciences software (SPSS version 16.0) is employed for between-group differences in demographics and clinical parameters among groups.

\section{Results}

The right and left HGM volumes are calculated by SPM and Marsbar as described in the previous section. Figure 2 shows the association between left and right HGM volumes in the $\mathrm{AD}$ and NC participants based on sex. The volume for the left and right HGM of each subject are calculated and accumulated. Table 2 presents the means and standard deviations for HGM volumes (ml), separately among the four groups of subjects. In addition, Figure 3 shows the HGM volume ( $\mathrm{ml}$ ) for all groups.

According to Table 2 and Figure 3, it is clear that AD participants show smaller HGM volume, as compared to age-matched normal participants in both male and female subjects. The reduction in HGM region is 1.38 times more in female cohort against male cohort. Results of ANOVA among four groups of participants, using HGM volume as the criterion variable, are presented in Table 3. The ANOVA test shows significant differences in HGM volume among four groups $(F(3,135)=28.29, \mathrm{p}<$ 0.05). Comparing the results of statistical mean between patients with $\mathrm{AD}$ and normal

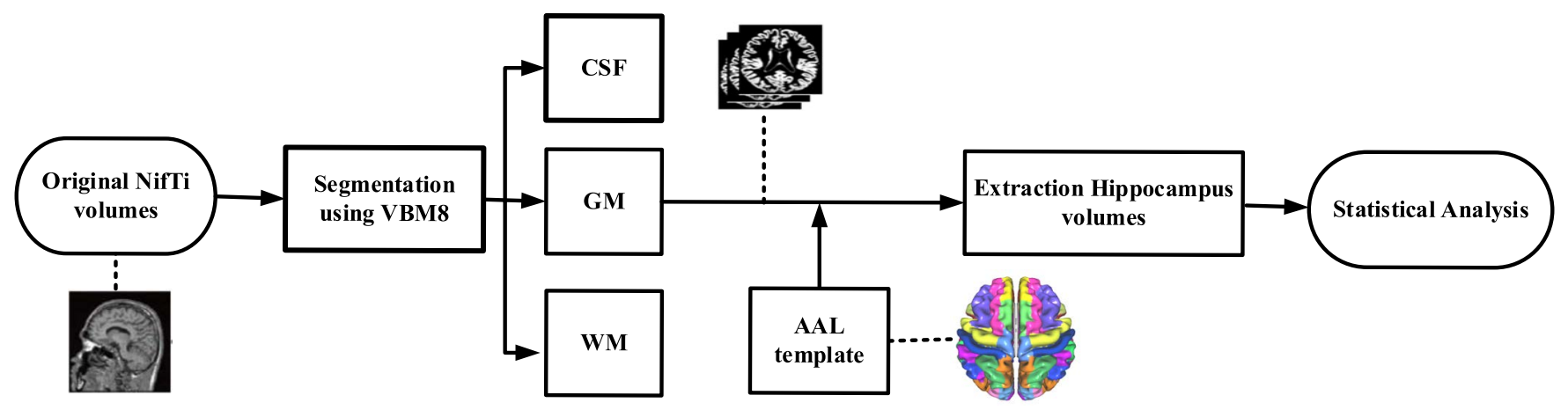

Figure 1. The pipeline of propsed system for calculation hippocampus volumes. 


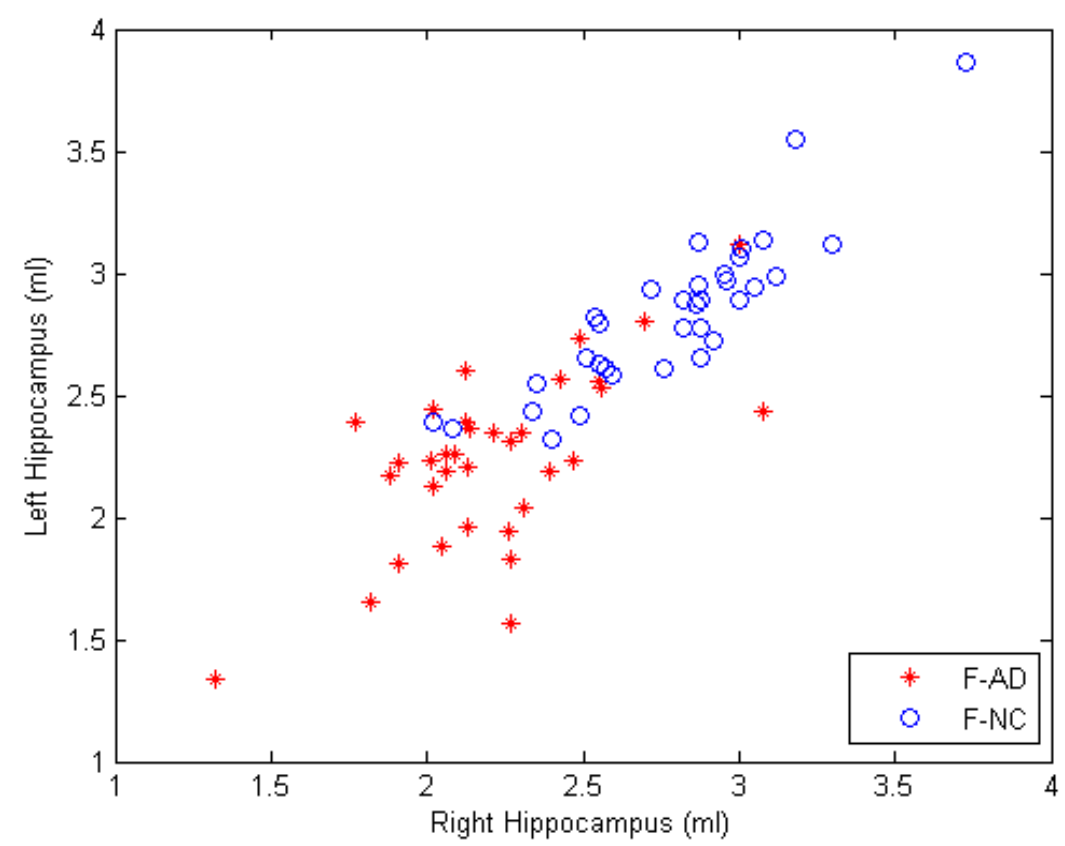

(a)

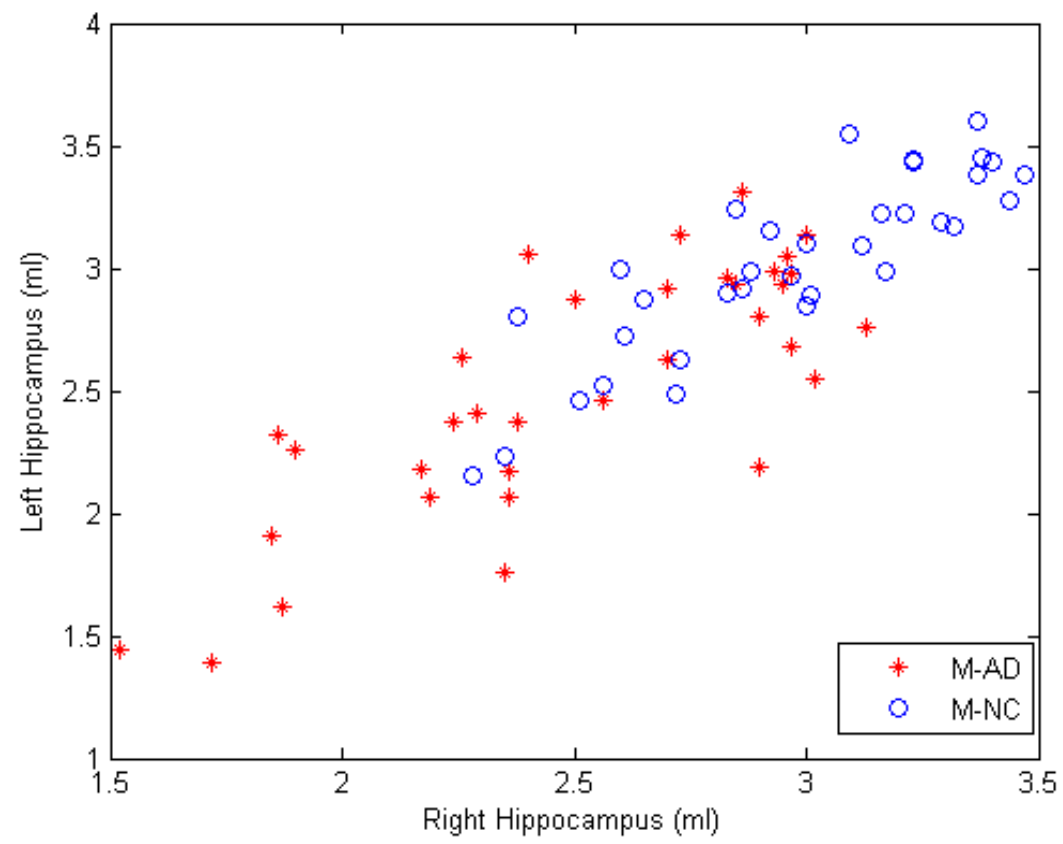

(b)

Figure 2. The association between left and right HGM volumes between AD and NC subjects according to sex. (a) Female subjects, (b) Male subjects.

Table 2. HGM volume measurement in the four groups.

\begin{tabular}{ccccc}
\hline & F-AD & F-NC & M-AD & M-NC \\
\hline HGM (ml) & $4.44 \pm 0.63$ & $5.61 \pm 0.64$ & $5.05 \pm 0.94$ & $5.99 \pm 0.68$ \\
\hline
\end{tabular}

Note: All data are presented in mean \pm standard deviation mode; F, Female; M, Male; AD, people with Alzheimer's Disease; NC, Normal Control participants; HGM, Hippocampus gray matter. 


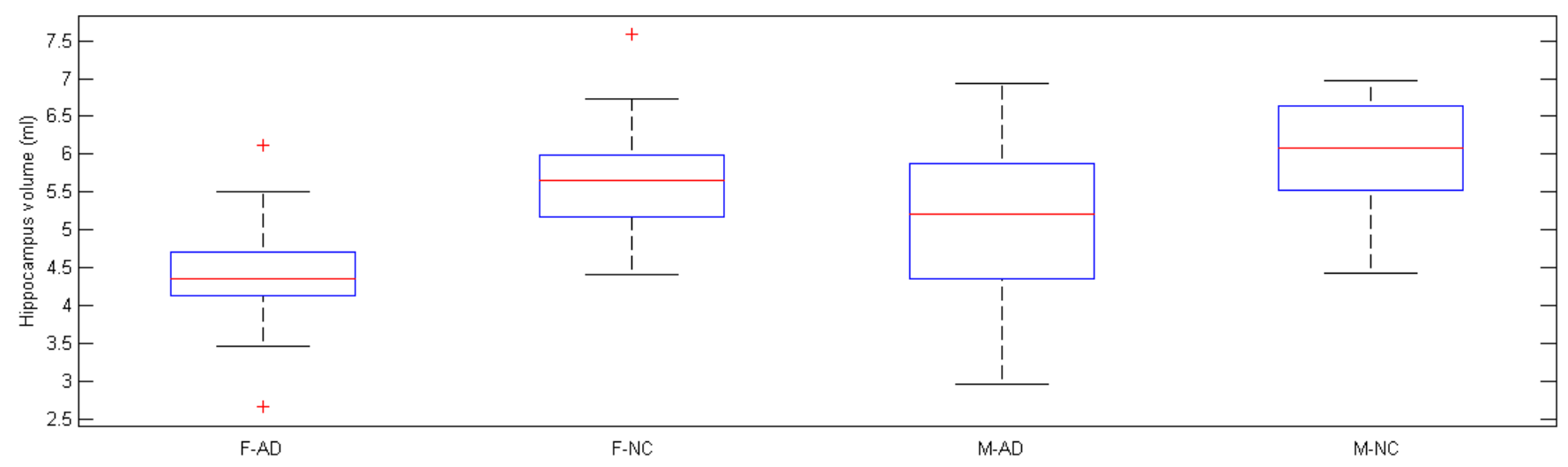

Figure 3. The HGM volumes (ml) for the four groups. F, Female; M, Male; AD, people with Alzheimer's disease; NC, Normal Control participants.

Table 3. Comparative mean of HGM volumes in the four groups.

\begin{tabular}{|c|c|c|c|c|}
\hline Variable & F-AD & F-NC & M-AD & M-NC \\
\hline F-NC & $1.17^{\star}$ & ------ & $0.56^{\star}$ & -0.37 \\
\hline M-AD & $0.60^{*}$ & $-0.56^{*}$ & ------ & $-0.93^{*}$ \\
\hline $\mathrm{F}$ & \multicolumn{4}{|c|}{28.29} \\
\hline
\end{tabular}

Note: F, Female; M, Male; AD, people with Alzheimer's Disease; NC, Normal Control participants; HGM, Hippocampus gray matter; MD, mean difference; F, F test; ${ }^{*} \mathrm{p}<0.05$.

controls in both male and female subjects clearly shows that female encounters more significant atrophy (M.D $=1.17, \mathrm{p}<0.05)$ compared to male $(\mathrm{M} . \mathrm{D}=0.93, \mathrm{p}<0.001)$ in HGM. In parallel to this outcome, female has more severity of disease in their limbic system.

\section{Discusion}

The Hippocampus, as part of brain, is responsible for emotion, memory, and the autonomic nervous system. In [8], we used a statistical analysis by VBM plus DARTEL to examine global and regional GM atrophy patterns in people with $\mathrm{AD}$, according to sex. In more detail, VBM plus DARTEL analysis demonstrated greater global GM reduction in the female subjects (F-AD versus F-NC), compared to the male subjects (M-AD versus $\mathrm{M}-\mathrm{NC}$ ). In this study, we focused on HGM volumes in patients with $\mathrm{AD}$ compared to normal controls based on sex. The results of this study revealed that the reduction in HGM region is around 1.38 times more in female against male subjects. Our statistical analysis suggests that there may be a link between HGM atrophy and AD based on the sex. This funding supports our previous study that sex is an important factor in the AD [8]. 


\section{Conclusion}

In conclusion, a statistical analysis (ANOVA) is used to investigate HGM volume in people who suffer from $\mathrm{AD}$, according to sex. The results have considerable implications for the development of therapies for those with this disease. The statistical results indicate that $\mathrm{AD}$ causes different HGM atrophy in the males and females. The HGM atrophy volume is higher in females, compared to males. This might be a reason why females with $\mathrm{AD}$ show more reclusive behavior, emotional lability, hoarding, and refusal of help. The results indicated that there is a significant role of sex on HGM atrophy in patients with $\mathrm{AD}$.

\section{Acknowledgements}

This work was partly carried out under the Brain Mapping by Integrated Neuroethologies for Disease Studies (Brain/MINDS) project (grant number 16dm0207017h0003), funded by the Japan Agency for Medical Research and Development (AMED). This work has been also partially supported by project grants from Beijing Nova Program (xx2016120), National Natural Science Foundation of China (81101107), Natural Science Foundation of Beijing (4162008) and program for top young innovative talents of the Beijing Educational Committee (CIT \& TCD201404053).

\section{References}

[1] Alzheimer's Association (2015) Alzheimer's Disease and Dementia. http://www.alz.org/

[2] Liu, S., Cai, W., Wen, L., Feng, D.D., Pujol, S., Kikinis, R., Fulham, M.J. and Eberl, S. (2014) Multi-Channel Neurodegenerative Pattern Analysis and Its Application in Alzheimer's Disease Characterization. Comput. Med. Imaging Graph., 38, 436-444. http://dx.doi.org/10.1016/j.compmedimag.2014.05.003

[3] Fjell, A.M., McEvoy, L., Holland, D., Dale, A.M., Walhovd, K.B., Initiative, A.D.N., et al. (2014) What Is Normal in Normal Aging? Effects of Aging, Amyloid and Alzheimer's Disease on the Cerebral Cortex and the Hippocampus. Prog. Neurobiol., 117, 20-40. http://dx.doi.org/10.1016/j.pneurobio.2014.02.004

[4] Intlekofer, K.A. and Cotman, C.W. (2013) Exercise Counteracts Declining Hippocampal Function in Aging and Alzheimer's Disease, Neurobiol. Dis., 57, 47-55. http://dx.doi.org/10.1016/i.nbd.2012.06.011

[5] Tang, X., Qin, Y., Wu, J., Zhang, M., Zhu, W. and Miller, M.I. (2016) Shape and Diffusion Tensor Imaging Based Integrative Analysis of the Hippocampus and the Amygdala in Alzheimer's Disease. Magn. Reson. Imaging., 34, 1087-1099. http://dx.doi.org/10.1016/j.mri.2016.05.001

[6] Mufson, E.J., Mahady, L., Waters, D., Counts, S.E., Perez, S.E., DeKosky, S., Ginsberg, S.D., Ikonomovic, M.D., Scheff, S. and Binder, L. (2015) Hippocampal Plasticity during the Progression of Alzheimer's Disease. Neuroscience. http://dx.doi.org/10.1016/j.neuroscience.2015.03.006

[7] Weiner, M.W., Veitch, D.P., Aisen, P.S., Beckett, L.A., Cairns, N.J., Green, R.C., Harvey, D., Jack, C.R., Jagust, W., Liu, E., Morris, J.C., Petersen, R.C., Saykin, A.J., Schmidt, M.E., Shaw, L., Shen, L., Siuciak, J.A., Soares, H., Toga, A.W. and Trojanowski, J.Q. (2015) 2014 Update of the Alzheimer's Disease Neuroimaging Initiative: A Review of Papers Published 
Since Its Inception. Alzheimer's Dement, 11, e1-e120.

http://dx.doi.org/10.1016/j.jalz.2014.11.001

[8] Beheshti, I., Demirel, H. and Yang, C. (2015) Significance of Sex Differences on Gray Matter Atrophy in Alzheimer's Disease : A Voxel-Based Morphometry Study. Br. Biomed. Bull., 3, 522-536.

[9] Carter, C.L., Resnick, E.M., Mallampalli, M. and Kalbarczyk, A. (2012) Sex and Gender Differences in Alzheimer's Disease: Recommendations for Future Research. J. Women's Heal., 21, 1018-1023. http://dx.doi.org/10.1089/jwh.2012.3789

[10] Vemuri, P. and Jack, C.R. (2010) Role of Structural MRI in Alzheimer's Disease. Alzheimers. Res. Ther., 2, 23. http://dx.doi.org/10.1186/alzrt47

[11] Beheshti, I., Olya, H.G.T. and Demirel, H. (2016) Risk Assessment of Alzheimer's Disease using the Information Diffusion Model from Structural Magnetic Resonance Imaging. J. Alzheimer's Dis., 52, 1-8. http://dx.doi.org/10.3233/JAD-151176

Submit or recommend next manuscript to SCIRP and we will provide best service for you:

Accepting pre-submission inquiries through Email, Facebook, LinkedIn, Twitter, etc.

A wide selection of journals (inclusive of 9 subjects, more than 200 journals)

Providing 24-hour high-quality service

User-friendly online submission system

Fair and swift peer-review system

Efficient typesetting and proofreading procedure

Display of the result of downloads and visits, as well as the number of cited articles

Maximum dissemination of your research work

Submit your manuscript at: http://papersubmission.scirp.org/

Or contact jbise@scirp.org 